\title{
ALIGNMENT OF LEAGILE STRATEGIES WITH OFF-SITE MANUFACTURING: APPLICATION OF ANP IN AUSTRALIAN HOUSING SUPPLY
}

\author{
Sherif Mostafa \\ School of Natural and Built Environments \\ University of South Australia \\ Adelaide, SA, Australia \\ E-mail: Sherif.mostsafa@mymail.unisa.edu.au \\ Jantanee Dumrak \\ The Federation University at IBIIT \\ Adelaide, SA, Australia \\ E-mail: Jantanee.d@gmail.com
}

\begin{abstract}
The supply response of Australian housing has not been commensurate with the growing demand. Four main factors affecting the Australian housing supply are house completion time, cost of finished house, customer preferences and level of skilled labor. Off-site manufacturing (OSM) could become a key innovation for the future of Australian house building as it provides capacity in meeting the growing housing demand, green construction and lesser requirements for labor force. OSM is a modern construction method in which house building components are produced in offsite factories and then transported to the construction site to be assembled. The supply responsiveness of OSM can be enhanced by employing lean and agile concepts. In this study, four leagile strategies are introduced to facilitate decision making based on different combinations of housing supply factors. This paper presents a matching of the four strategies with the four studied factors in the Australian house building using Analytical Network Process (ANP). The data employed for the ANP model derived from the actual specifications of 258 houses built in five Australian States by five major house builders in Australia. The results from the ANP model show the suitability in applying each strategy under different degrees influenced by the factors tested.
\end{abstract}

Keywords: Australian housing supply, Leagile strategies, ANP, Off-site manufacturing.

\section{Introduction}

The residential building is one of the leading sectors in Australian economy. It consists of many independent building organizations to construct separate houses, semi-detached houses, townhouses, flats, units and apartments (Dowling 2005). In 2010-2011, the sector reported significant production value of AUD 47 billion. However, the responsiveness of the values of work commenced in residential building is unlikely to keep pace with the growth of other construction activities (ABS 2012). This situation is caused by the imbalance of housing supply and demand. In regard to the shortage of housing supply situation (COAG 2012; Gharaie, Wakefield \& Blismas 2010; HIA 2011; NHSC 2013) and neglect in the housing supply challenges (Liu \& London 2011), this paper, therefore, mainly focuses on the Australian housing problems from supply perspectives. This paper addresses four main factors including house construction costs, house completion time, level of skilled labor, and house customer preferences affecting the Australian housing supply. It is evident that more research is required to explore the applicability of Off-Site Manufacturing (OSM) as a new construction method to improve the house building supply in Australia (Blismas \& Wakefield 2009; Hampson \& Brandon 2004).

In this research, the aim is to enhance the OSM uptake in Australia by integrating lean and agile concepts. Four leagile strategies are introduced to manage the OSM house building supply chain. The results of this study will answer the research question: "How can house builders optimize the use of 
IJAHP Article: Mu, Saaty/A Style Guide for Paper Proposals To Be Submitted to the International Symposium of the Analytic Hierarchy Process 2014, Washington D.C., U.S.A.

leagile strategies?” The outcome of the research could lead to adoption of the suitable OSM strategies for Australian house builders.

\section{Literature Review}

The accumulative housing supply shortage has been predicted (COAG 2012) and confirmed by the housing industry alliances such as the National Housing Supply council (NHSC), Housing Industry Association (HIA), and Master Builders Australia (Dalton, Wakefield \& Horne 2011). As from the periods of June 2011 to June 2031, the housing supply and affordability report produced by NHSC (2012) projects the gaps between the underlying demand and supply in housing from all scenarios. In low build rate, the difference between demand and supply is forecasted to reach 415,000, 943,000 and $1,558,000$ dwellings in low, medium, and high demand growth respectively. For the high demand growth, the expected shortage of dwellings will be 1,558,000, 1,050,000, and 447,000 dwellings respectively.

It is foreseen that the practice of OSM will gradually play a major part in Australian house building in the coming decades (Hampson and Brandon 2004). The opportunities to adopt OSM in Australia centered on detached houses, high-density multi-residential complexes, and public facilities such as hospitals and schools. The development of OSM will expand to walling systems, modularized housing and light weight concrete wall panels (Blismas \& Wakefield 2009). Despite the potential of OSM in Australia, the uptake of OSM has been limited due to some barriers such as the builders conservatism influenced by the limited success in the past, high fragmentation in the construction industry, a lack of codes and standards, loss of control on-site and into supply chain, lack of skilled labors, and insufficient industry investment in research and development. Employing some concepts such as lean and agile manufacturing could contribute to success in enhancing OSM uptake in the house building industry (Blismas 2007; Hampson \& Brandon 2004; Manley, Mckell \& Rose 2009). Four different leagile strategies introduced in this paper are Make-To-Stock (MTS), Assemble-To-Order (ATO), Design-ToOrder (DTO) and Self-Build-House (SBH). Using Analytic Network Process (ANP) will enable the house builders to select the most appropriate strategy that fits their supply conditions.

\section{Hypotheses/Objectives}

The aim of this study is to introduce OSM house building supply strategies to Australian house builders. To achieve this aim, five research objectives have been developed:

- To highlight the factors contributing to Australian housing undersupply

- To overview the potential of OSM in Australian housing environment

- To demonstrate an integrative framework of lean and agile (leagile) in OSM house building supply chain

- To create a decision support model for house builders to optimize the use of the leagile strategies in order to enhance the OSM adoption in Australia

\section{Research Design/Methodology}

In this paper, it is contended that the four main factors influenced the housing supply in Australia. These factors impact on the selection of house building supply chain strategies. The ANP is a technique in multi-criteria decision analysis (MCDA) based on relative assessment of both tangible and intangible criteria (Ozdemir, 2005).The ANP, from Saaty and Vargas (2013), can be used to optimize the selection of four leagile house building strategies in respect to the key factors affecting the housing undersupply in Australia. Data were collected from various resources related to the Australian housing including peer reviewed journals, reference books, websites, and Australian housing authorities including National Housing Supply Council (NHSC), Housing Industry Association (HIA), Australian Bureau of Statistics (ABS), Australian Housing and Urban Research Institute (AHURI), and Council of Australian Governments (COAG). The collected materials were carefully examined and allocated reference numbers to facilitate the data analysis process. Then, the possible factors affecting the imbalance between housing supply and demand in Australia were determined.

International Symposium of the Analytic Hierarchy

Process
2

Washington, D. C.

June 29 - July 2, 2014 
The goal of the proposed ANP model was to select the suitable strategy under different circumstances of house building factors. The criteria were the four factors mentioned above. Each criterion was further divided into sub-criteria (Figure 1). The four suggested leagile strategies were placed as the alternatives. The Housing 100 Report for the year 2013 presented the Australia's largest 100 builders (HIA, 2013). Their main housing activities contributed around $75 \%$ of the housing supply. In this paper, the top five potential builders of supplying houses in five Australian States Western Australia (WA), South Australia (SA), New South Wales (NSW), Victoria (VIC), and Queensland (QLD) were selected. The five builders were capable of adopting the four leagile strategies. This adoption capacity was enhanced by their house building work in the five states, market share, decision making and the future trends during the period of 2011-2013 (HIA, 2011, 2013). The strategies would allow builders to make decision to tailor their house building activities. The weightings of the criteria and sub-criteria for each strategy were grounded on the specifications of actual 258 houses. The specifications obtained were classified into groups under each criterion and sub-criterion before pairwise comparisons conducted to predict the most suitable strategy.

\section{Data/Model Analysis}

The simple network model for associating the main house undersupply factors and leagile strategies is demonstrated in Figure 1. The model contains five clusters. The first cluster represents the house completion time factor. Under house completion time, there are two nodes namely number of houses under construction and house construction method. The house building costs cluster includes material and labor costs nodes. The third cluster is the level of skilled labor which includes contractors and trade persons. The house customer preferences cluster contains three nodes of house floor area, house location and façade options. The last cluster represents the alternatives which are the four leagile strategies. The model network, comparisons and assessments among the clusters and nodes were created and performed using Super Decisions Software. Figure 2 demonstrates a sample of pairwise comparisons from the software. After pairwise comparisons, the priorities of alternatives were synthesized from the criteria and sub-criteria. The overall rating of the four leagile house building strategies are displayed in Figure 3. The findings in the ANP model indicated that SBH acted as the best strategy. Therefore, this strategy should be suggested for the Australian house building.

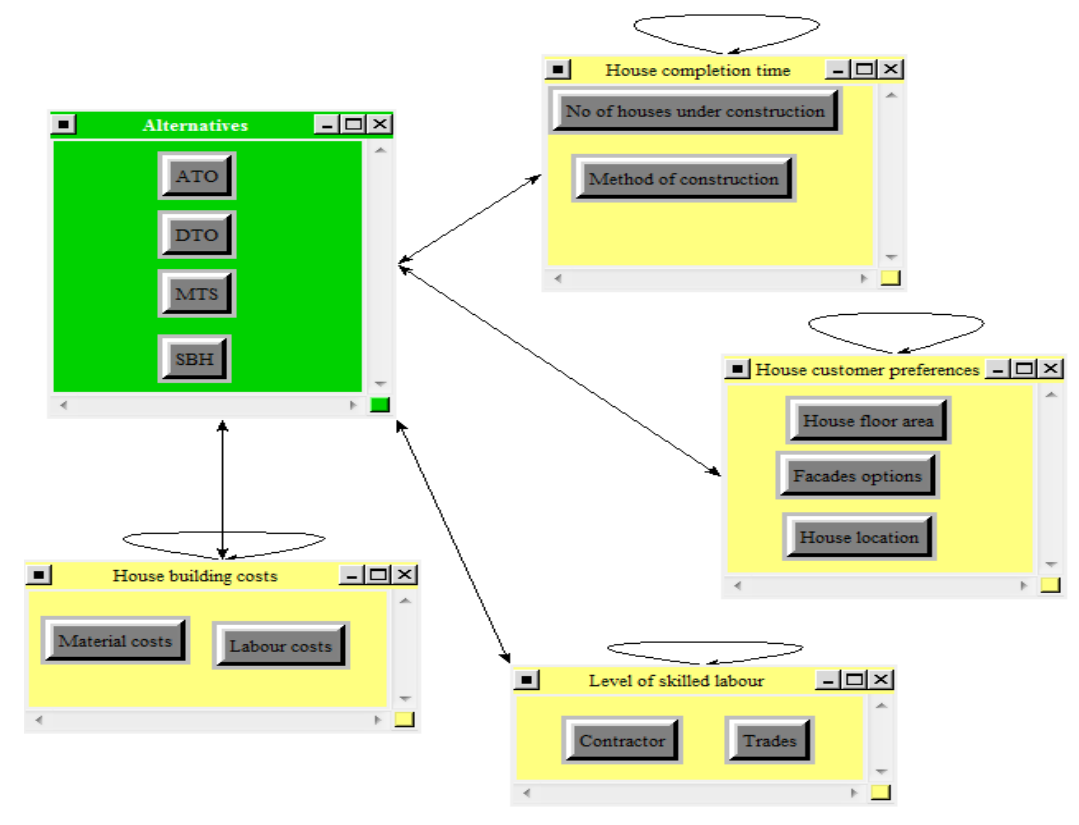

Figure 1. Suggested ANP model to associate the leagile strategies with house shortage factors in Australia 
IJAHP Article: Mu, Saaty/A Style Guide for Paper Proposals To Be Submitted to the International Symposium of the Analytic Hierarchy Process 2014, Washington D.C., U.S.A.

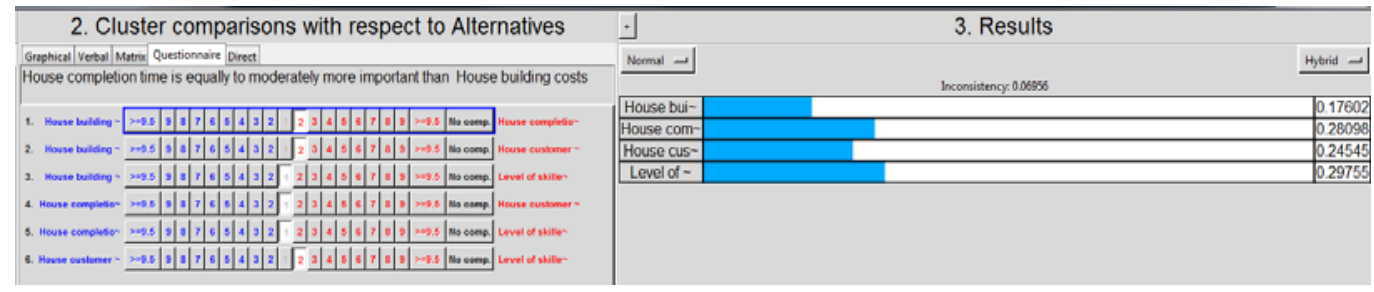

Figure 2. Cluster comparisons with respect to alternatives

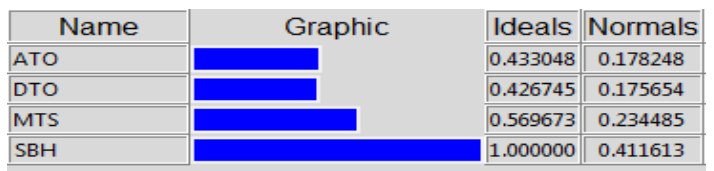

Figure 3. Rating of the leagile strategies

\section{Limitations}

This study utilized the actual specifications data from 258 houses built by the top five Australian builders. Each specification was extracted and placed according to the categories established. The development of ANP model in this study was subject to the data released by the builders and secondary data sources on Australian house building. More housing undersupply factors could be further searched and added to future study to extend the research boundaries. Other factors such as coordination and scheduling among the stakeholders, land supply, and demographic factors (e.g., economic circumstances of household, number of overseas migrations) may be included. Moreover, future research could conduct surveys with the Australian house building experts (e.g., house builders, residential developers, architects, and house owners) in order to verify or to refine the ANP model displayed in this study.

\section{Conclusions}

The Australian house building sector has experienced shortage in housing supply. The house customer preferences, house building costs, completion time and level of skilled labor add more complexities to the design specifications. Furthermore, house customer demands are ambiguous and changed dynamically. The four strategies proposed in this paper attempted to respond to the factors causing supply shortage and to balance the trade-off between house builders and customers. This study was carried out using the ANP model to optimize the selection of the leagile OSM strategies with respect to the main factors contributing to the shortage of housing supply in Australia. The findings from the ANP model indicated that SBH was the most suitable strategy among the four strategies proposed for the combination of factors tested. Therefore, this strategy should be suggested to the Australian house builders.

\section{Key References}

ABS 2012, 2012 Year Book Australia, Australian Bureau of Statistics, Canberra.

Blismas, N. 2007, Off-site manufacture in Australia: Current state and future directions, Cooperative Research Centre for Construction Innovation, Brisbane.

Blismas, N. \& Wakefield, R. 2009, Drivers, constraints and the future of offsite manufacture in Australia, Construction Innovation: Information, Process, Management, vol. 9, no. 1, pp. 72-83.

COAG 2012, Housing Supply and Affordability Reform, Council of Australian Government's, Canberra. 
IJAHP Article: Mu, Saaty/A Style Guide for Paper Proposals To Be Submitted to the International Symposium of the Analytic Hierarchy Process 2014, Washington D.C., U.S.A.

Dalton, T., Wakefield, R. \& Horne, R. 2011, Australian suburban house building: industry organisation, practices and constraints.

Dowling, R. 2005, Residential building in Australia, 1993-2003, Urban Policy and Research, vol. 23, no. 4, pp. 447-464.

HIA, 2013, Housing 100: Australia’s Largest Homebuilders and Residential Developers 2012/2013, ACT.

Gharaie, E., Wakefield, R. \& Blismas, N. 2010, Explaining the Increase in the Australian Average House Completion Time: Activity-based versus Workflow-based Approach, Australasian Journal of Construction Economics and Building, vol. 10, no. 4, pp. 34-49.

Hampson, K.D. \& Brandon, P. 2004, Construction 2020-A Vision For Australia's Property And Construction Industry, CRC Construction Innovation, Brisbane, QLD.

HIA 2011, Housing to 2020 : The states of Australian housing to the year 2020, Housing Industry Association Economics Group, Campbell ACT, Australia.

Liu, J. \& London, K. 2011, Analysing the Relationship between New Housing Supply and Residential Construction Costs with Regional Heterogeneities, Australasian Journal of Construction Economics and Building, vol. 11, no. 3, pp. 58-67.

Manley, K., Mckell, S. \& Rose, T. 2009, Innovative Practices in the Australian Built Environment Sector: An Information Resource for Industry, Brisbane, QLD.

NHSC 2012, Housing Supply and Affordability: Key Indicators, National Housing Supply Council, Canberra ACT, Australia.

NHSC 2013, Housing supply and affordability issues 2012-13, National Housing Supply Council Canberra.

Ozdemir, M. S., 2005, The unknown in decision making: The case of a network, Proceedings of the $8^{\text {th }}$ International Symposium on the Analytic Hierarchy Process: Multi-criteria Decision Making, Honolulu, Hawaii, USA.

Saaty, T.L., \& Vargas, L.G. (2013), Decision Making with the Analytic Network Process Economic, Political, Social and Technological Applications with Benefits, Opportunities, Costs and Risks, Springer, Boston, MA. 